Do Hands-Free Cell Phone Conversation While Driving Increase the Risk of Cognitive Distraction Among Drivers? A Cross-Over

\title{
Quasi-Experimental Study
}

Farideh Sadeghian, ${ }^{1,2}$ Mojgan Karbakhsh, ${ }^{3}$ Mahnaz Saremi, ${ }^{4}$ Iraj Alimohammadi, ${ }^{5}$ Hassan Ashayeri, ${ }^{6}$ Mahsa Fayaz, ${ }^{7}$ Maryam Rezaei, ${ }^{8}$ and Soheil Saadat ${ }^{1,}$

${ }^{1}$ Sina Trauma and Surgery Research Center, Tehran University of Medical Sciences (TUMS), Tehran, Iran

${ }^{2}$ Department of Occupational Health, School of Public Health, Shahroud University of Medical Sciences, Shahroud, Iran

${ }^{3}$ Department of Community Medicine, School of Medicine, Tehran University of Medical Sciences, Tehran, Iran

${ }^{4}$ Department of Ergonomics, School of Health, Safety and Environment, Shahid Beheshti University of Medical Sciences, Tehran, Iran

${ }^{5}$ Department of Occupational Health Engineering, School of Public Health, Iran University of Medical Sciences, Tehran, Iran

${ }^{6}$ Department of Basic Sciences in Rehabilitation, School of Rehabilitation Sciences, Iran University of Medical Sciences, Tehran, Iran

${ }^{7}$ Department of Epidemiology and Biostatistics, School of Public Health, Shahroud University of Medical Sciences, Shahroud, Iran

${ }^{8}$ Toronto Western Hospital, Toronto, Canada

"Corresponding author: Soheil Saadat, Sina Hospital, Hassan-Abad Square, Imam Khomeini Ave, Tehran, Iran. Tel: +98-2166757001-5, Fax: +98-2166757009, E-mail: soheilsaadat@sina.tums.ac.ir

Received 2017 May 10; Revised 2017 August 05; Accepted 2017 October 21.

\section{Abstract}

Background: Background: Conversation over the cell phone while driving is a known risk factor for road traffic crash. Using handsfree to talk on the cell phone may remove visual and manual distraction yet not the cognitive distraction.

Objectives: The purpose of this study was to better understand the mechanisms of cognitive distraction due to hands-free cell phone conversation (HFPC) while driving.

Methods: Twelve male and 12 female University students in Tehran, Iran, were selected via the consecutive convenient sampling method, and randomly assigned to one of the following administrations of cross-over quasi-experimental study design, during year 2016: Administration 1, participants performed the tests while involved in HFPC, took rest for 60 minute, and then performed the tests another time without HFPC; Administration 2, participants performed the tests without HFPC, took rest, and then performed the tests another time with HFPC. Each participant moved to the other administration after 7 to 10 days. The Vienna test system (VTS) was used to measure simple and choice reaction time, selective attention, visual orientation, and visual memory. Linear regression analysis was used to study the change in test scores due to HFPC.

Results: The mean age of participants was $27.1 \pm 5.3$ years. A history of road traffic crash (regardless of severity) was reported among 9 (37.5\%) participants in the previous year. Hands-free cell phone conversation while driving was directly associated with mean time correct rejection score $(\mathrm{P}<0.01)$ (selective attention), omitted response $(\mathrm{P}<0.01)$ and median reaction time $(\mathrm{P}<0.01)(\mathrm{choice}$ reaction time), and mean reaction time $(\mathrm{P}<0.01)$ (Simple reaction time). Moreover, HPFC was inversely associated with sum hits $(\mathrm{P}$ $=0.05)$ (selective attention), incorrect $(\mathrm{P}<0.02)$ and correct response $(\mathrm{P}<0.01)$ (choice reaction time), score based on viewing and working time $(\mathrm{P}<0.01)$ (visual orientation), and visual memory performance $(\mathrm{P}<0.01)$.

Conclusions: Using hands-free devices to converse during driving, impaired reaction time, selective attention, visual orientation and visual memory, which are essential for safe driving. Thus, the use of these devices does not preclude cognitive distraction and should be restricted.

Keywords: Cognitive Distraction, Cell Phone, Hands Free, Reaction Time, Attention

\section{Background}

Road traffic crash (RTC) is the first cause of injury and the second leading cause of death in Iran in youth (1). Driving is a complex procedure of visual, manual, cognitive, and auditory tasks (2). Driver distraction from in-vehicle dual tasks, especially conversing on a cell phone $(3,4)$ is increasingly documented as a major cause of injuries and fa- talities (5), and considerable proportion of RTCs could be attributed to this behavior $(6,7)$. In $2013,21 \%$ of RTCs in the US were related to conversations with cell phones while driving, according to the national safety council (8).

A dose-response association between cell phone conversation frequency and incidence of RTC has been observed in many countries around the world (9-12). A study 
indicated that driver's conversations on the cell phone within 10 minutes preceding the RTC, increases the risk of crashing fourfold (13). Asbridge reported that talking on the phone during driving could raise the odds of a culpable RTC by $70 \%$ (14).

Fifty countries, including Iran, have banned the use of hand-held phones while driving (15). Laws that only ban drivers from using hand-held devices resulted in a rapid increase in hands-free cell phones conversation (HFPC) because it was assumed that HFPC is safe enough (16).

There are 3 sources for driving distraction due to secondary tasks, including visual, manual, and cognitive distraction (17). Hands-free cell phones conversation while driving can remove visual and manual distraction but not cognitive distraction. Cognitive distraction occurs when attention is withdrawn from the information processing that is needed for safe driving (17). Impairments of driving due to attention is linked to cognitive workload of invehicle activities (4). A driver's job is to lookout for risks, yet this process cannot be completed when the brain is overloaded (17). Mental workload impairs the spatial gaze of focused attention and visual-detection in actual traffic situations. Moreover, it makes the driver spend less time checking interior instruments and mirrors (18).

Previous studies have shown that HFPC could impair reaction time similar to having blood alcohol concentration of at least $0.05 \%(19,20)$. Other researches have indicated that HFPC behind the wheel has a negative impact on safe following distance from the car in front, glance length, divided attention, eye movement, lane keeping, and number of missed events $(17,21)$.

It has been reported that $10 \%$ of Iranian drivers use cell phones while driving, when they were observed on the road. This is higher than the prevalence reported in Australia, USA, and Canada (22).

This study was carried out to further understand the cognitive distraction due to HFPC while driving. All the measurements were done using the Vienna test system (VTS), which is an objective and reliable tool to measure the cognitive abilities of drivers $(23,24)$. This study measured score changes of simple and choice reaction time, selective attention, visual orientation, and visual memory as a result of HFPC. To the best of the author's knowledge, this is the first study that has utilized an objective tool of traffic psychology in this field in IRAN.

\section{Methods}

\subsection{Participants}

Twelve male and 12 female students of Tehran University of Medical Sciences (TUMS) in Tehran, Iran, aged 20 to
39 years participated in the study during year 2016. They had drivers' licenses and had been driving for at least one year before being included in this study. The participants were asked to abstain from coffee and sleeping pills during the 24 hours before the experiment. The participants were asked for their best attention and performance during the test and were rewarded by cash payment that was proportional to their performance and did not exceed 14 USD per test. The study protocol was approved by the research ethics committee of Tehran University of Medical Sciences (reference number: IR TUMS.REC.2015.1984- 7/12/2015), and written informed consent was obtained from all participants.

\subsection{Data Collection Tools}

Individual characteristics, history of RTC, and cellphone use habits were collected by a self-administered questionnaire.

\subsubsection{Computerized Traffic Psychological Test}

Traffic psychological test battery of the Vienna test system (VTS) was used to measure cognitive ability of driving. Previous researches have shown that the test results contribute significantly to the prediction of fitness to drive, in a standardized driving test (23-26). The following five tests of VTS were used in this study:

- Cognition test (COG) (S11 form): This test measures selective attention and concentration by comparison of one Figure with others concerning their congruence. The main variables of this test in the present study were "sum hits," "sum correct rejections", and "mean time correct rejections". These 3 variables measure the precision of the control of attention.

- Determination test (DT) (S1 form): This test measures complex choice reaction time and stress tolerance. The participant is needed to distinguish various colors and sounds to select the connected reactions. The main variables in this test were "median reaction time", "correct", "incorrect", and "omitted" responses.

- Visual pursuit test (LVT) (S3 form): This test measures visual orientation performance. The main variables of this test were "score based on working times" and "score based on viewing times".

- Reaction test(RT)(S3 form): This test measures simple reaction time with acoustic and optical stimuli (yellow and red lights). This form of the test includes 2 variables. The "mean reaction time" and "mean motor time".

-Visual memory test(VISGED)(S11 form): This test evaluates visual memory performance. The main variable of this test is "visual memory performance". 


\subsubsection{Simulated Hands-Free Phone Conversations (HPFC)}

The Rosenbaum verbal cognitive test battery was used to simulate a phone conversation. The battery included solving a puzzle, repeating a sentence, and talking on a specific topic (27). The participants were asked to answer the prerecorded questions that were played section by section using a speaker located on the left side of the participants to simulate a phone conversation. The instructor monitored the participants' answers.

\subsection{Study Design and Data Collection Procedures}

The study was of cross over design. Each participant was invited to practice with VTS one day before the trial. Participants were then divided to 2 groups by random allocation. In the first group, participants took the VTS tests while HPFC (simulated). After completing the tests, they took rest for 60 minutes and repeated the test without HPFC. The order in the second group was the reverse.

The participants then crossed to the other group and repeated the test in reverse order after 7 to 10 days. Therefore, 4 records were obtained from each participant: two while HPFC and two without HPFC. Figure 1 displays the study design.

\subsection{Statistical Analysis}

The sample size was estimated using power analysis and sample size software (Hintze, J. (2011). PASS 11. NCSS, LLC. Kaysville, Utah, USA. www.ncss.com), module for "Power Analysis of $2 \times 2$ Cross-Over Design for Testing Equivalence".

In a preliminary study, the mean reaction time of study participants was $360 \pm 38.2$ milliseconds. The estimated sample size to detect a $15 \%$ change in the reaction time with a power of $90 \%$ in a cross-over design was 12 . Therefore, 12 male and 12 female participants were included.

For univariate analysis, the student's test, $\chi^{2}$ or Fisher's exact test were used, as necessary. Continuous variables are presented as mean \pm standard deviation (SD).

Linear regression analysis was utilized to examine the association of VTS scores (dependent variables) with HPFC and also the order of the test (as the independent variables). The clustered nature of the data was taken into account using the "cluster" option. The normal distribution of the data was examined using the Kolmogorov- Simonov test, before the regression analysis. In case of deviation from normal distribution, the relevant transformation was done and the transformed values were used in regression analysis.

The effect modification role of gender was examined in the regression analysis and if there was an effect modification, the regression analysis was repeated for males and females separately.

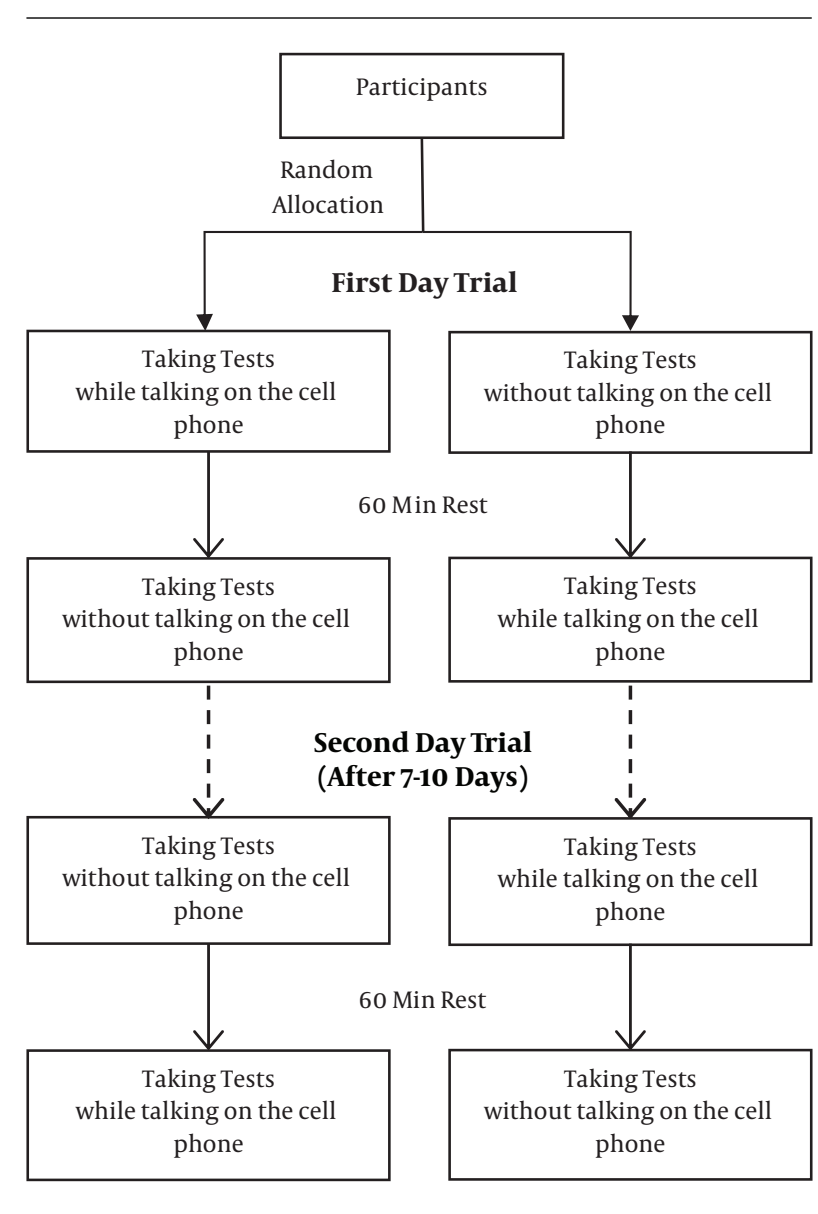

Figure 1. The Study Design

Data analysis was conducted using the SPSS software, version 21 and STATA 13 SE. The level of significance was set at $\mathrm{P}$ value $\leq 0.05$.

\section{Results}

Twelve male and 12 female university students with mean age of $27.1 \pm 5.3$ years were included in this study. Individual characteristics of the study participants are presented in Table 1. They had been driving for $6.8 \pm 4.7$ years. Reading incoming text and answering incoming calls while driving was reported among 15 (62.5\%) and 18 (75.0\%) of the participants, respectively. Nine individuals (37.5\%) reported RTC during the past year, regardless of severity. Mean \pm SD of subtest scores of VTS tests are presented in Table 2 .

Regression analysis showed that after controlling the effect of learning curve (the order of testing), HFPC was directly associated with the following subsets of VTS tests: 
Table 1. Characteristics, History of Road Traffic Collision and Cell-Phone Use Habits of Study Participants ${ }^{\mathrm{a}}$

\begin{tabular}{lccc}
\hline Variables & \multicolumn{2}{c}{ Gender } & \multirow{2}{*}{ P Value } \\
& Male & Female & \\
\hline Age & $26.3 \pm 4.7$ & $27.9 \pm 5.9$ & $\mathrm{P}=0.45^{\mathrm{b}}$ \\
\hline The age at starting to drive & $18.3 \pm 2.7$ & $22.3 \pm 5.9$ & $\mathrm{P}=0.04^{\mathrm{b}}$ \\
\hline $\begin{array}{l}\text { Number of RTC during past 12 } \\
\text { months }\end{array}$ & & & $\mathrm{P}=1^{\mathrm{c}}$ \\
\hline 0 & $7(58.3)$ & $8(66.7)$ & \\
\hline 1 & $2(16.7)$ & $1(8.3)$ & \\
\hline 2 & $3(25.0)$ & $2(16.7)$ & \\
\hline 3 & $0(0)$ & $1(8.3)$ & \\
\hline $\begin{array}{l}\text { Answering incoming calls while } \\
\text { driving }\end{array}$ & & & $\mathrm{P}=0.64^{\mathrm{c}}$ \\
\hline No & & & \\
\hline Yes / maybe & $2(16.7)$ & $4(33.3)$ & \\
\hline $\begin{array}{l}\text { Reading incoming text while } \\
\text { driving }\end{array}$ & $10(83.3)$ & $8(66.7)$ & \\
\hline No & & & \\
\hline Yes / maybe & & & \\
\hline
\end{tabular}

Abbreviation: RTC, Road Traffic Collision.

${ }^{\mathrm{a}}$ Values are expressed as No. (\%).

b based on Independent Sample T-Test.

${ }^{c}$ based on chi 2 or Fisher exact test.

mean time correct rejection score $(\mathrm{P}<0.01)$ (selective attention test), omitted response $(\mathrm{P}<0.01)$ and median reaction time $(\mathrm{P}<0.01)$ (choice reaction time test), and mean reaction time $(\mathrm{P}<0.01)$ (simple reaction time test). Moreover, HPFC was inversely associated with sum hits $(\mathrm{P}=0.05)$ (selective attention test), incorrect $(\mathrm{P}<0.02)$ and correct response $(\mathrm{P}<0.01)$ (choice reaction time test), score based on viewing and working time $(\mathrm{P}<0.01)$ (visual orientation test), and visual memory performance $(\mathrm{P}<0.01)$ (visual memory test) (Table 3).

There was evidence of effect modification of gender, on the association between HPFC and some of the VTS subtests. Table 4 shows the coefficients of HPFC among male and female participants for this subset of VTS tests.

\section{Discussion}

The purpose of this study was to measure the association of HFPC during driving with cognitive distraction. The main outcome was that drivers' cognitive abilities were greatly associated with HFPC while driving. The findings confirmed that people are likely to be less accurate and rapid in the case of HFPC compared with the condition, in which no conversation exists. This impairment was ob- served in simple and choice reaction times, selective attention, visual orientation, and visual memory.

The impairment could be explained by multiple resource theory (MRT) of cognition (28). Based on the fact that a limited set of resources are available for human mental processing, the MRT asserts that humans merge different kinds of cognitive resources, including attention, short and long-term memory, reasoning and so on, to resolve problems. In dual-task situations, 2 separate tasks were implemented, making possible debate on how to solve each one by essential cognitive resources. Shifting resources from one task to another can improve the performance on the second task $(29,30)$ and as the difficulty of one task increases, the performance on the other declines (31).

The results revealed that simple and choice reaction time deteriorated with HFPC. This means that participants' abilities to react rapidly and properly in the extended orders of reaction tasks were decreased. These findings are in line with previous studies (17, 32-34). In a study conducted by Kaur et al., comparison of mean reaction times in 3 conditions of hands-free, hands-held cell phone conversation, and no conversation indicated a significantly longer reaction time due to both hands-free and hands-held conversations compared to the no-conversation condition. However, the rise of percentage from their baseline auditory reaction time was greater in the case of conversing with hands-free than with hand-held phones (33). In a similar study designed by Hendricks JL et al., results indicated significant increase in reaction times, movement times, and total response times for both hands-free and hand-held phone conversations in comparison with no phone use (34).

However, in the current study, the mean motor time, was not affected by HFPC. Reaction time included processing of information and attention properties, whereas movement time was related to muscle contraction (35). It seems that HFPC delays the process of decision making rather than delaying motor response.

Regarding gender and its effect on reaction time of drivers, the current results showed that the impairments among males was greater than females. This is in line with another study that reported although males indicated significantly shorter reaction times than females, both during single and dual tasks, the percentage increase from their baseline reaction times during both hand held and hands free cellphone conversation, was greater in males (33). On the other hand, Hancock et al. reported that the corresponding impairments was stronger in females (36).

In the current study, in accordance with Amado et al. (37), selective attention diminished with HFPC. Selective attention was among the most important cognitive abilities for safe driving so that its impairment could predict traffic 
Table 2. The Mean \pm SD Cognitive Ability of Driving Test Score with and without Cell Phone Conversation on the First and Second Trial ${ }^{\mathrm{a}}$

\begin{tabular}{|c|c|c|c|c|}
\hline \multirow[t]{2}{*}{ Tests } & \multicolumn{2}{|c|}{ First Trial } & \multicolumn{2}{|c|}{ Second Trial } \\
\hline & $\begin{array}{l}\text { With Cell Phone } \\
\text { Conversation }\end{array}$ & $\begin{array}{c}\text { Without, Cell Phone } \\
\text { Conversation }\end{array}$ & $\begin{array}{l}\text { With Cell Phone } \\
\text { Conversation }\end{array}$ & $\begin{array}{c}\text { Without Cell Phone } \\
\text { Conversation }\end{array}$ \\
\hline \multicolumn{5}{|l|}{ COG( selective attention) } \\
\hline Sum hits & $23.13 \pm 0.99$ & $23.29 \pm 0.91$ & $22.83 \pm 1.09$ & $23.42 \pm 0.65$ \\
\hline Sum correct rejections & $34.75 \pm 1.19$ & $35.08 \pm 1.32$ & $34.67 \pm 1.24$ & $34.83 \pm 1.20$ \\
\hline $\begin{array}{l}\text { Mean time correct } \\
\text { rejection }\end{array}$ & $2.97 \pm 0.80$ & $2.09 \pm 0.61$ & $2.86 \pm 1.10$ & $2.03 \pm 0.52$ \\
\hline \multicolumn{5}{|l|}{ DT(choice reaction time) } \\
\hline Correct response & $202.58 \pm 38.12$ & $280.04 \pm 29.38$ & $195.042 \pm 36.31$ & $287.04 \pm 33.87$ \\
\hline Incorrect response & $12.62 \pm 7.99$ & $17.46 \pm 11.93$ & $12.08 \pm 6.27$ & $15.75 \pm 13.90$ \\
\hline Omitted response & $26.25 \pm 9.63$ & $10.58 \pm 5.38$ & $26.79 \pm 8.57$ & $10.12 \pm 6.49$ \\
\hline Median reaction time & $0.80 \pm 0.07$ & $0.70 \pm 0.06$ & $0.81 \pm 0.08$ & $0.70 \pm 0.06$ \\
\hline \multicolumn{5}{|l|}{ LVT (visual orientation) } \\
\hline $\begin{array}{l}\text { Score (based on } \\
\text { viewing times) }\end{array}$ & $12.67 \pm 3.92$ & $15.17 \pm 2.24$ & $12.29 \pm 3.64$ & $14.46 \pm 2.86$ \\
\hline $\begin{array}{l}\text { Score (based on } \\
\text { working times) }\end{array}$ & $14.62 \pm 2.48$ & $16.08 \pm 1.44$ & $13.92 \pm 2.84$ & $15.92 \pm 2.22$ \\
\hline \multicolumn{5}{|l|}{ RT (simple reaction time) } \\
\hline Mean reaction time & $443.17 \pm 47.90$ & $366.13 \pm 38.20$ & $466.00 \pm 61.02$ & $358.13 \pm 46.19$ \\
\hline Mean motor time & $111.67 \pm 26.95$ & $109.00 \pm 29.30$ & $110.83 \pm 26.41$ & $105.83 \pm 23.04$ \\
\hline \multicolumn{5}{|l|}{$\begin{array}{l}\text { VISGED (Visual } \\
\text { memory) }\end{array}$} \\
\hline $\begin{array}{l}\text { Visual memory } \\
\text { performance }\end{array}$ & $1.75 \pm 1.61$ & $3.11 \pm 1.30$ & $1.22 \pm 1.74$ & $3.01 \pm 1.30$ \\
\hline
\end{tabular}

${ }^{\mathrm{a}}$ Values are expressed as mean $\pm \mathrm{SD}$.

collisions (38).

The current findings confirmed that visual orientation decreased with HFPC. The brain copes with various visual, auditory, manual, and cognitive tasks necessary for driving (17). When a distracted (e.g. by cell-phone conversation) driver "looks at the scene, he or she may not see up to $50 \%$ of the data in the driving situation" (39). Once people challenged to do more than one cognitively complex task receive too much information, the brain changes its focus and does not transfer some visual information to the working memory. If this "inattention blindness" occurs, the central data falls out of observation and is not processed by the brain. Consequently, a distracted driver cannot recognize and react to potential hazards (40). Just et al. made functional Magnetic Resonance Images (fMRI) of the brain, where subjects drove on a simulator and listened to verbal sentences on their cell phones. Results showed that the activity of parietal lobe of the brain, an area associated with driving activity, was reduced by $37 \%$. This part of the brain is essential for orientation and the type of spatial processing related to driving. Therefore, listening and verbal conception drew cognitive resources from driving and resulted in interlacing of lane and strike to guardrails by drivers (41).

Visual memory performance of the participants showed a reduction by HFPC. One possible explanation is when drivers are distracted, they make fewer essential driving-related procedures and their alertness may be diminished (42). Another explanation is related to the limited capacity of visual short-term memory (VSTM) to only 4 or 5 items (43) that embrace new visual data. When VSTM is engaged, no extra information could be encoded, even though they are "seeing". Therefore, any distraction that occupies VSTM will decrease the possibility that a given part of driving-related data will be paid proper attention. Consequently, distractions caused by HFPC are able to influence safe driving. It has been shown that involvement in HFPC, impairs the perception of changes in real traffic sights (44) and drivers often fail to remember the details of items they had observed (45). 
Table 3. Association of Cognitive Ability of Driving Tests with Hands-Free Cell Phone Conversations (HFPC)

\begin{tabular}{|c|c|c|c|c|}
\hline Dependent Variables & Independent Variables & Coefficient & $0.95 \% \mathrm{CI}$ & PValue \\
\hline \multicolumn{5}{|l|}{ COG (selective attention) } \\
\hline \multirow{2}{*}{ Sum hits } & HFPC & -0.38 & $-0.74,-0.01$ & 0.05 \\
\hline & The order of test & -0.08 & $-0.42,0.25$ & 0.61 \\
\hline Sum correct rejections & HFPC & -0.25 & $-0.77,0.27$ & 0.33 \\
\hline \multirow{2}{*}{ Mean time correct rejection } & HFPC & 0.86 & $0.63,1.09$ & $<0.01$ \\
\hline & The order of test & -0.09 & $-0.23,0.05$ & 0.22 \\
\hline \multicolumn{5}{|l|}{ DT (choice reaction time) } \\
\hline \multirow{2}{*}{ Correct response } & HFPC & -84.73 & $-93.78,-75.67$ & $<0.01$ \\
\hline & The order of test & -0.27 & $-7.92,7.38$ & 0.94 \\
\hline Incorrect response & The order of test & -1.13 & $-2.82,0.57$ & 0.18 \\
\hline \multirow{2}{*}{ Omitted response } & HFPC & 16.17 & $13.70,18.63$ & $<0.01$ \\
\hline & The order of test & 0.04 & $-2.16,2.24$ & 0.97 \\
\hline \multirow{2}{*}{ Median reaction time } & HFPC & 0.11 & $0.09,0.12$ & $<0.01$ \\
\hline & The order of test & 0.00 & $-0.01,0.01$ & 0.85 \\
\hline \multicolumn{5}{|l|}{ LVT (visual orientation) } \\
\hline \multirow{2}{*}{ Score (based on viewing time) } & HFPC & -2.33 & $-3.31,-1.35$ & $<0.01$ \\
\hline & The order of test & -0.54 & $-1.34,0.25$ & 0.17 \\
\hline \multirow{2}{*}{ Score (based on working times) } & HFPC & -1.73 & $-2.52,-0.94$ & $<0.01$ \\
\hline & The order of test & -0.44 & $-1.11,0.24$ & 0.19 \\
\hline \multirow{2}{*}{ Mean reaction time } & HFPC & 92.46 & $79.20,105.72$ & $<0.01$ \\
\hline & The order of test & 7.42 & $-5.26,20.09$ & 0.24 \\
\hline \multirow{2}{*}{ Mean motor time } & HFPC & 3.83 & $-4.44,12.11$ & 0.35 \\
\hline & The order of test & -2.00 & $-7.46,3.46$ & 0.46 \\
\hline \multicolumn{5}{|l|}{ VISGED (visual memory) } \\
\hline \multirow{2}{*}{ Visual memory performance } & HFPC & -1.58 & $-2.05,-1.10$ & $<0.01$ \\
\hline & The order of test & -0.31 & $-0.89,0.27$ & 0.28 \\
\hline
\end{tabular}

Abbreviation: CI: Confidence Interval.

\subsection{Strengths and limitations}

This was a semi-experimental study and most of the variables that could affect the test results were selfmatched. Therefore, the study had solid validity and reliability.

The extent of deterioration of those affected aspects of psychomotor performance was quantified, by using an objective approach. The measurements were made using a standard computerized fitness to drive system and standard conversation. To the best of the author's knowledge, the present study was the first that benefited from this level of internal validity in Iran.

There were some limitations in this study. The generalization of the results may be limited to only 20- to 40-yearold educated people. Further studies with heterogeneous driver samples are required to address this limitation.

This study examined the extent of impairment in driving oriented cognition in male and female participants. However, the study was not specifically designed to compare the level of impairment in driving ability between males and females. Further specifically designed studies 
Table 4. Association of Cognitive Ability of Driving Tests with Hands Free Cell-Phone Conversation by Gender

\begin{tabular}{|c|c|c|c|c|c|}
\hline Dependent Variables & Gender & Independent Variables & Coefficient & $0.95 \%$ CI & P Value \\
\hline \multicolumn{6}{|l|}{ COG } \\
\hline \multicolumn{6}{|c|}{ Mean time correct rejection } \\
\hline & \multirow{2}{*}{ Male } & HFPC & 1.02 & $0.64,1.41$ & $<0.01$ \\
\hline & & The order of test & -0.01 & $-0.22,0.19$ & 0.91 \\
\hline & \multirow{2}{*}{ Female } & HFPC & 0.69 & $0.41,0.97$ & $<0.01$ \\
\hline & & The order of test & -0.16 & $-0.38,0.06$ & 0.13 \\
\hline \multicolumn{6}{|l|}{ LVT } \\
\hline \multicolumn{6}{|c|}{ Score (based on viewing time) } \\
\hline & \multirow{2}{*}{ Male } & HFPC & -1.5 & $-2.67,-0.32$ & 0.02 \\
\hline & & The order of test & 0.17 & $-0.84,1.18$ & 0.72 \\
\hline & \multirow{2}{*}{ Female } & HFPC & -1.96 & $-3.22,-0.69$ & $<0.01$ \\
\hline & & The order of test & -1.04 & $-1.95,-0.13$ & 0.03 \\
\hline \multicolumn{6}{|l|}{ RT } \\
\hline \multicolumn{6}{|c|}{ Mean reaction time } \\
\hline & \multirow{2}{*}{ Male } & HFPC & 102.37 & $80.53,124.22$ & $<0.01$ \\
\hline & & The order of test & 12.62 & $-6.82,32.07$ & 0.18 \\
\hline & \multirow{2}{*}{ Female } & HFPC & 82.54 & $65.71,99.37$ & $<0.01$ \\
\hline & & The order of test & 2.21 & $-17.13,21.55$ & 0.81 \\
\hline
\end{tabular}

Abbreviation: $\mathrm{CI}$, Confidence Interval.

are required to elaborate any gender difference in this field.

\subsection{Conclusion}

This study quantified the effect of HFPC on cognitive functions, which are essential for safe driving. It further confirmed impairment of cognitive ability of drivers due to HFPC in 5 domains, including simple and choice reaction time, selective attention, visual orientation, and visual memory. The main finding of this study was that HFPC while driving should not be considered safe.

\section{Acknowledgments}

The study was supported by Sina trauma and surgery research center (NO.30427) affiliated to Tehran University of Medical Sciences. The authors would like to appreciate all participants.

\section{Footnotes}

Authors' Contribution: Study concept and design, Soheil Saadat and Farideh Sadeghian; acquisition of data, Farideh
Sadeghian; analysis and interpretation of data, Soheil Saadat and Farideh Sadeghian; drafting of the manuscript, Farideh Sadeghian; critical revision of the manuscript for important intellectual content, Soheil Saadat, Farideh Sadeghian, Mojgan Karbakhsh, Mahnaz Saremi, Iraj Alimohammadi, Hassan Ashayeri, Mahsa Fayaz, and Maryam Rezaei; statistical analysis, Soheil Saadat and Mahsa Fayaz; administrative, technical, and material support, Soheil Saadat; study supervision, Soheil Saadat.

Financial Disclosure: The authors declare that they had no conflicts of interest.

\section{References}

1. Azami-Aghdash S, Abolghasem Gorji H, Sadeghi-Bazargani H, Shabaninejad H. Epidemiology of road traffic injuries in Iran: based on the data from disaster management information system (DMIS) Of the Iranian red crescent. Iran Red Crescent Med J. 2016;19(1). doi: 10.5812/ircmj.38743.

2. Haque MM, Washington S. A parametric duration model of the reaction times of drivers distracted by mobile phone conversations. Accid Anal Prev. 2014;62:42-53. doi: 10.1016/j.aap.2013.09.010. [PubMed: 24129320].

3. Beanland V, Fitzharris M, Young KL, Lenne MG. Driver inattention and driver distraction in serious casualty crashes: data from the Aus- 
tralian National Crash In-depth Study. Accid Anal Prev. 2013;54:99-107. doi: 10.1016/j.aap.2012.12.043. [PubMed: 23499981].

4. Strayer DL, Turrill J, Cooper JM, Coleman JR, Medeiros-Ward N, Biondi F. Assessing Cognitive Distraction in the Automobile. Hum Factors. 2015;57(8):1300-24. doi: 10.1177/0018720815575149. [PubMed: 26534847].

5. National Highway Traffic Safety Administration. Traffic Safety Facts Research Note: Distracted Driving 2013, DOT HS 812:132. 2015.

6. Sussman ED, Bishop H, Madnick B, Walter R. Driver inattention and highway safety. Transp Res Rec. 1985;1047:40-8.

7. Wang JS, Knipling RR, Goodman MJ. The role of driver inattention in crashes: New statistics from the 1995 Crashworthiness Data System. 40th annual proceedings of the Association for the Advancement of Automotive Medicine. 1996.

8. National Safety Council . Annual Estimate of Cell Phone Crashes. 2013

9. Horberry T, Bubnich C, Hartley L, Lamble D. Drivers' use of hand-held mobile phones in Western Australia. Transp Res Part F Traffic Psychol Behav. 2001;4(3):213-8. doi: 10.1016/s1369-8478(01)00022-5.

10. Sullman MJM, Baas PH. Mobile phone use amongst New Zealand drivers. Transp Res Part F Traffic Psychol Behav. 2004;7(2):95-105. doi: 10.1016/j.trf.2004.03.001.

11. Hallett C, Lambert A, Regan MA. Cell phone conversing while driving in New Zealand: prevalence, risk perception and legislation. Accid Anal Prev. 2011;43(3):862-9. doi: 10.1016/j.aap.2010.11.006. [PubMed: 21376877].

12. Backer-Grøndahl A, Sagberg F. Driving and telephoning: Relative accident risk when using hand-held and hands-free mobile phones. Saf Sci. 2011;49(2):324-30. doi: 10.1016/j.ssci.2010.09.009.

13. McEvoy SP, Stevenson MR, McCartt AT, Woodward M, Haworth C, Palamara P, et al. Role of mobile phones in motor vehicle crashes resulting in hospital attendance: a case-crossover study. BMJ. 2005;331(7514):428. doi: 10.1136/bmj.38537.397512.55. [PubMed: 16012176].

14. Asbridge $\mathrm{M}$, Brubacher JR, Chan $\mathrm{H}$. Cell phone use and traffic crash risk: a culpability analysis. Int J Epidemiol. 2013;42(1):259-67. doi: 10.1093/ije/dys180. [PubMed: 23159829].

15. Wikipedia . Mobile phones and driving safety. 2016. Available from: https://en.wikipedia.org/wiki/Mobile_phones_and_driving_safety, 12/22/16.

16. World Health Organization . Mobile phone use: a growing problem of driver distraction. 2011.

17. National Safety Council . Understanding the distracted brain: Why driving while using hands-free cell phones is risky behavior. White Paper; 2012.

18. Recarte MA, Nunes LM. Mental workload while driving: effects on visual search, discrimination, and decision making. J Exp Psychol Appl. 2003;9(2):119-37. doi:10.1037/1076-898X.9.2.119. [PubMed: 12877271]

19. Lamble D, Kauranen T, Laakso M, Summala H. Cognitive load and detection thresholds in car following situations: safety implications for using mobile (cellular) telephones while driving. Accid Anal Prev. 1999;31(6):617-23. doi: 10.1016/S0001-4575(99)00018-4. [PubMed: 10487336].

20. Burns P, Parkes A, Burton S, Smith R, Burch D. How Dangerous is Driving with a Mobile Phone?: Benchmarking the Impairment to Alcohol. TRL; 2002.

21. National Safety Council. Why driving while using hands-free cell phones is risky behavior. 2010. Available from: www.fnal.gov/pub/traffic_ safety/files/NSC/White/Papermarch2010.

22. Arvin R, Khademi M, Razi-Ardakani H. Study on mobile phone use while driving in a sample of Iranian drivers. Int J Inj Contr Saf Promot. 2017;24(2):256-62. doi: 10.1080/17457300.2016.1175480. [PubMed: 27184136].

23. Sommer M, Heidinger C, Arendasy M, Schauer S, Schmitz-Gielsdorf J, Hausler J. Cognitive and personality determinants of post-injury driving fitness. Arch Clin Neuropsychol. 2010;25(2):99-117. doi: 10.1093/arclin/acp109. [PubMed: 20080833]
24. Risser R, Chaloupka C, Grundler W, Sommer M, Hausler J, Kaufmann C. Using non-linear methods to investigate the criterion validity of traffic-psychological test batteries. Accid Anal Prev. 2008;40(1):149-57. doi: 10.1016/j.aap.2006.12.018. [PubMed: 18215543].

25. Schuhfried G. Manual expert system traffic (XPSV). Mödling: Schuhfried $\mathrm{GmbH} ; 2005$

26. Aniței M, Chraif M, Schuhfried G, Sommer M. The validation of expert system traffic psychological assessment to romanian driving schools. Procedia Soc Behav Sci. 2011;30:457-64. doi: 10.1016/j.sbspro.2011.10.090.

27. Waugh JD, Glumm MM, Kilduff PW, Tauson RA, Smyth CC. Pillalamarri RS: Cognitive workload while driving and talking on a cellular phone or to a passenger. Proceedings of the Human Factors and Ergonomics Society Annual Meeting: 2000. CA: Los Angeles. SAGE Publications Sage; 2000.

28. Wickens CD. Multiple resources and performance prediction. Theor Issues Ergon Sci. 2002;3(2):159-77. doi:10.1080/14639220210123806.

29. Navon D, Gopher D. On the economy of the human-processing system. Psychol Rev. 1979;86(3):214-55. doi:10.1037/0033-295x.86.3.214.

30. Norman DA, Bobrow DG. On data-limited and resource-limited processes. Cogn Psychol.1975;7(1):44-64. doi:10.1016/0010-0285(75)90004 3.

31. Wickens CD, Sandry DL, Vidulich M. Compatibility and resource competition between modalities of input, central processing, and output. Hum Factors.1983;25(2):227-48. doi:10.1177/001872088302500209. [PubMed: 6862451].

32. Parkes A, Burns P, Burton S, Smith R, Luke T, Lansdown T. Conversations in cars: The relative hazards of mobile phones final report. 2003.

33. Kaur M, Nagpal S, Singh H, Suhalka M. Effect of dual task activity on reaction time in males and females. Indian I Physiol Pharmaco. 2014;58(4):389-94. [PubMed: 26215006].

34. Hendrick JL, Switzer JR. Hands-free versus hand-held cell phone conversation on a braking response by young drivers. Percept Mot Skills. 2007;105(2):514-22. doi: 10.2466/pms.105.2.514-522. [PubMed: 18065072]

35. Bellinger DB, Budde BM, Machida M, Richardson GB, Berg WP. The effect of cellular telephone conversation and music listening on response time in braking. Transp Res Part F Traffic Psychol Behav. 2009;12(6):441-51. doi: 10.1016/j.trf.2009.08.007.

36. Hancock PA, Lesch M, Simmons L. The distraction effects of phone use during a crucial driving maneuver. Accid Anal Prev. 2003;35(4):501-14. doi:10.1016/S0001-4575(02)00028-3. [PubMed:12729814].

37. Amado S, Ulupinar P. The effects of conversation on attention and peripheral detection: Is talking with a passenger and talking on the cell phone different?. Transp Res Part F Traffic Psychol Behav. 2005;8(6):38395. doi: 10.1016/j.trf.2005.05.001.

38. Arthur W, Doverspike D. Locus of control and auditory selective attention as predictors of driving accident involvement: A comparative longitudinal investigation. J Safety Res. 1992;23(2):73-80. doi: 10.1016/0022-4375(92)90023-3.

39. Strayer DL. Presentation at Cell Phones and Driver Distraction. Washing ton DC: Traffic Safety Coalition; 2007

40. Strayer DL, Drews FA, Johnston WA. Inattention-blindness behind the wheel.J Vis. 2010;3(9):157. doi: 10.1167/3.9.157.

41. Just MA, Keller TA, Cynkar J. A decrease in brain activation associated with driving when listening to someone speak. Brain Res. 2008;1205:70-80. doi: 10.1016/j.brainres.2007.12.075. [PubMed: 18353285].

42. Kass SJ, Cole KS, Stanny CJ. Effects of distraction and experience on situation awareness and simulated driving. Transp Res Part F Traffic Psychol Behav. 2007;10(4):321-9. doi: 10.1016/j.trf.2006.12.002.

43. Luck SJ, Vogel EK. The capacity of visual working memory for features and conjunctions. Nature. 1997;390(6657):279-81. doi: 10.1038/36846. [PubMed: 9384378].

44. McCarley JS, Vais MJ, Pringle H, Kramer AF, Irwin DE, Strayer DL. Con- 
versation disrupts change detection in complex traffic scenes. Hum Factors. 2004;46(3):424-36. doi: 10.1518/hfes.46.3.424.50394. [PubMed: 15573543].
45. Strayer DL, Drews FA, Johnston WA. Cell phone-induced failures of visual attention during simulated driving. J Exp Psychol Appl. 2003;9(1):23-32. [PubMed: 12710835]. 